\title{
Association between tooth loss rate and risk of mild cognitive impairment in older adults: a population-based longitudinal study
}

\author{
Shuyu Xu ${ }^{1}$, Xi Huang ${ }^{2}$, Yin Gong ${ }^{2}$, Jiangwei Sun ${ }^{3}$ \\ ${ }^{1}$ Department of Implantology, School and Hospital of Stomatology, Shanghai Engineering Research Center of \\ Tooth Restoration and Regeneration, Tongji University, Shanghai, China \\ ${ }^{2}$ Department of Stomatology, First Affiliated Hospital of Soochow University, Jiangsu Province, China \\ ${ }^{3}$ Institute of Environmental Medicine, Karolinska Institute, Stockholm, Sweden
}

Correspondence to: Xi Huang, Yin Gong; email: huangxist@163.com, https://orcid.org/0000-0002-0870-4235;

gy20041986@163.com, https://orcid.org/0000-0003-0994-3470

Keywords: tooth loss, mild cognitive impairment, longitudinal study, elderly, China

Received: July 15, $2021 \quad$ Accepted: August 19, $2021 \quad$ Published: September 7, 2021

Copyright: $(2021 \mathrm{Xu}$ et al. This is an open access article distributed under the terms of the Creative Commons Attribution License (CC BY 3.0), which permits unrestricted use, distribution, and reproduction in any medium, provided the original author and source are credited.

\section{ABSTRACT}

Mild cognitive impairment $(\mathrm{MCl})$ is a symptomatic predementia phase of the trajectory of cognitive decline, and its prevalence increases with age. Although the relationship between oral health and $\mathrm{MCl}$ have been explored previously, it is uncertain whether individuals with different tooth loss rates have altered $\mathrm{MCl}$ risks. We hereby conducted a longitudinal study by using data from the Chinese Longitudinal Healthy Longevity Survey to investigate the association. Tooth loss rate was defined as the difference of teeth between two interview waves divided by years of interval; participants were then grouped into four categories: stable, no tooth loss; mild, 0-1 tooth loss; middle, 1-2 tooth loss; and severe, more than 2 tooth loss per year. Cognitive function was assessed by the Chinese version of Mini-Mental State Examination. We used the generalized estimating equation model to estimate the odds ratio (OR) and the $95 \%$ confidence intervals (Cls) and applied the restricted cubic spline function to explore the dose-response association. Among 11,862 participants, 3,966 developed $\mathrm{MCl}$ in a median follow-up time of 5.93 years. Higher tooth loss rate was associated with an increased risk of $\mathrm{MCl}$ in elderly subjects. Compared with subjects with stable tooth, the corresponding ORs (95\% Cls) were $0.94(0.85-1.03), 1.16(1.04-1.29)$ and $1.28(1.17-1.40)$ for subjects with the mild, middle and severe rate of tooth loss. A nonlinear dose-response relationship was detected $\left(\boldsymbol{P}_{\text {non-linearity }}=\mathbf{0 . 0 1 6 5}\right)$. Similar results were observed in the subgroup analyses stratified by sex, age at baseline, and number of teeth at baseline. The positive association was only observed among denture nonwearers (OR middle vs stable: 1.19; 1.061.35; OR severe vs stable: $1.35 ; 1.22-1.50)$, but not among denture wearers. In conclusion, among elderly population in China, higher rate of tooth loss may be associated with an increased risk of $\mathrm{MCl}$, while denture wearers may be less likely to develop $\mathrm{MCl}$.

\section{INTRODUCTION}

Aging, a natural process of life, is often accompanied by various disorders or diseases including cognitive impairment [1]. Cognitive impairment is characterized by the gradual loss of one's ability in learning, remembering, concentrating, and making decisions [2]. Mild cognitive impairment (MCI) is the clinical stage between the expected cognitive decline of normal aging and dementia [2]. Its incidence rate widely ranges by age [3]: 22.5 per 1,000 person-years for aged $75-79,40.9$ for aged 80-84, and 60.1 for aged over 85 years [3]. In China, the incidence rate of MCI was estimated to be 70.57 per 1,000 person-years for aged over 60 years, [4] with a prevalence of $15.5 \%$, representing 38.77 million people [5]. With huge impacts on the quality of life for patients, the global economic burden of dementia is estimated to be more than 800 billion USD [6]. 
The strongest risk factors of MCI included old age and having a specific form of a gene known as APOE e4, which is also linked to Alzheimer's disease [7-9]. Epidemiological studies have also identified other medical conditions and lifestyles as risk factors for MCI, including high blood pressure, diabetes mellitus, depression, low education level, less frequent participation in stimulating activities mentally or socially, smoking, low vegetable and high saturated fat consumption [8-10].

Oral diseases are one age-related health problem that is common among elderly adults [11]. The need for dental treatment however has been unmet among elderly people, especially in the developing countries [11, 12]. Previous studies have suggested that oral health is associated with cognitive function, but the results of periodontal disease were conflicting [13]. Recent prospective evidence indicated that less teeth at baseline may be associated with cognitive decline in elderly people [14], this hypothesis was further supported by the evidence from a meta-analysis, which showed that tooth loss was related to an increased risk of MCI and dementia [13]. Evidence from longitudinal studies revealed that denture wearing, through increasing nutritional intake and encouraging social participation, was associated with lower risk of MCI and other health-related outcomes such as cardiovascular and respiratory disease mortality $[15,16]$. However, another longitudinal study, conducted in participants aged 70-79 years in US, did not report a significant association between tooth loss and cognitive decline [17].

As previous studies varied in study quality and result, the relationship between tooth loss and MCI risk in elderly adults remains inconclusive. Besides, previous studies usually use number of teeth in a specific time point (e.g., baseline) as the exposure to reflect the oral health status $[14,18]$, which cannot track the dynamic change of teeth with aging. Number of tooth loss per year may be a more suitable indicator to reflect its dynamic change.

Therefore, to explore the effect of change in teeth number on MCI risk, we conducted a longitudinal study to explore their associations in elderly Chinese population. The dose-response association between them was also investigated in the present study.

\section{RESULTS}

\section{Baseline characteristics of study population}

Among 11,862 participants [age at baseline: 81.41 years; male: 6,047 (50.98\%)], 3,966 developed MCI in a median follow-up time of 5.93 (interquartile range:
3.67-9.62) years (Table 1 and Figure 1). A total of $4,705,2,016,1,687$, and 3,454 subjects were classified into groups of stable, mild, middle, and severe rate of tooth loss, respectively. Compared with participants with stable status, participants with severe rate of tooth loss were more likely to be younger, to be farmer or manual workers, to live in rural area, to have more teeth and higher physical performance score and food diversity score at baseline; but less likely to be married, ever or current exerciser, and to wear denture at baseline (Table 1).

\section{Association between tooth loss rate and risk of MCI}

Results from model 1 to model 4 was robust. We found that higher tooth loss rate was associated with an increased risk of MCI in elderly participants. Compared with subjects with stable teeth, the corresponding ORs were 0.94 (95\%CI: 0.85-1.03), 1.16 (95\%CI: 1.04-1.29) and 1.28 (95\% CI: $1.17-1.40)$ for subjects with the mild, middle and severe rate of tooth loss in model 4 (Table 2). As shown in Figure 2, there was a nonlinear dose-response relationship between number of tooth loss (per year) and risk of MCI in the whole population $(P$ non-linearity $=0.0165)$. The risk of MCI sharply increased in the initial stage but gradually tended to be flat with the increasing of number of tooth loss.

Similar results were also observed in the subgroup analyses based on sex and age at baseline. For severe rate of tooth loss, there was a $20 \%$ increased risk of MCI (1.04-1.37) for men, while 37\% (1.20-1.55) for women. The corresponding ORs were 1.33 (1.13-1.56), 1.33 (1.15-1.53) and $1.23(1.03-1.48)$ for participants with 65-79 years, $80-89$ years, and $\geq 90$ years at baseline (Table 2 and Figure 3).

In the subgroup analysis by number of teeth at baseline, we found that severe rate of tooth loss was associated with increased risk of MCI, and the risk was higher for subjects with number of teeth less than $17(1.34 ; 1.18$ 1.51) than for subjects with number of teeth more than 17 at baseline $(1.21 ; 1.05-1.41)$ (Table 3$)$. Similar result was also observed in the dose-response analysis (Figure 3).

However, when stratified by denture wearing at baseline, the positive association of higher rate of tooth loss with risk of MCI was only observed among denture nonwearers $(\mathrm{OR}$ middle vs stable $=1.19 ; 1.06-1.35 ; \mathrm{OR}$ severe vs stable $=1.35 ; 1.22-1.50)$. No association was observed among denture wearers (Table 3 and Figure 3).

\section{DISCUSSION}

In this longitudinal study among elderly adults in China, we found that higher tooth loss rate was associated 
Table 1. Baseline characteristics in elderly adults, a longitudinal study in China, 1998 to 2019.

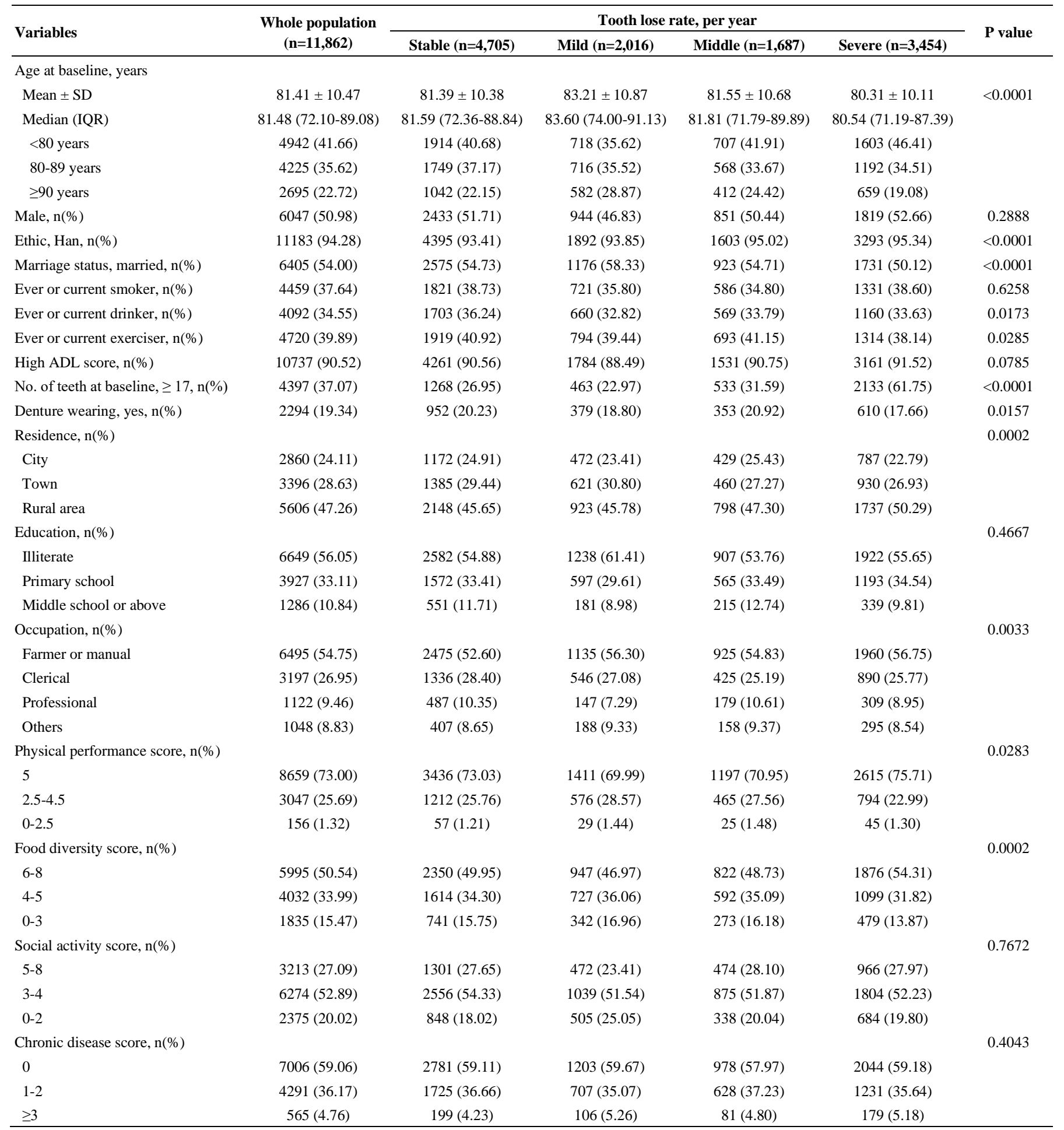

Abbreviations: ADL, activities of daily living; IQR, interquartile range; SD, standard deviation.

with an increased risk of MCI in a non-linear relationship, and severe rate of tooth loss was related to a $28 \%$ increased risk of MCI. The results were robust across a series of subgroup analyses by sex, age and number of teeth at baseline. However, the positive association of higher rate of tooth loss with MCI risk was disappeared among subjects with denture wearing at baseline. These findings added new evidence to the relationship between oral health and cognitive function. 
Our results are consistent with previous studies in elderly adults. Previous longitudinal studies indicated that number of teeth at baseline was associated with cognitive decline among older adults [13, 14, 19]. Participants with more teeth suggested a slower pace of cognitive decline over time, when comparing with those with fewer teeth $[14,20]$. However, another US longitudinal study reported that fewer teeth at baseline was not significantly associated with cognitive decline [17]. This inconsistency might be caused by difference in ethnicity, enrolled age distribution, follow-up period, and definition of cognitive decline. For example, the follow-up period to evaluate cognitive decline in the US cohort was only 2 years, [17] while the present study had a relatively longer follow-up period (median follow-up time: 5.93 years). Moreover, instead of using the teeth number at baseline as the exposure, our study used tooth loss rate as the exposure, which could capture the information on the dynamic change of the tooth with aging. In addition, the present study found that $19.34 \%$ participants wore denture at baseline, and that increased risk of MCI was disappeared among denture wearers, which suggested that denture wearing may provide an effect against the developing of MCI. Previous cohort studies also found that denture wearing provided a protective effect against death for all degrees of tooth loss. [16].

There are several possible mechanisms to explain the association between tooth loss and risk of MCI. First, periodontitis is a chronic inflammatory oral disease and a major cause of tooth loss [21]. It shares two pathological features of Alzheimer's disease namely oxidative damage and inflammation [22]. Oral pathogens and their toxic molecules, after disseminating into the bloodstream, may induce a low-grade systemic inflammation through upregulating the release of cytokines and inflammatory mediators, which can trigger neuroinflammation and cause neuronal degeneration [23-25]. Second, tooth loss may lead to poor nutrition status, caused by insufficient consumption of recommended levels of foods and nutrients. Poor nutrition status, such as vitamin B deficiency, has been suggested to be related to cognitive decline [26, 27]. Of note, denture wearing could effectively increase nutritional intakes, which may subsequently improve the cognitive function [28, 29]. Additionally, previous studies have shown that denture wearing could encourage social participation, which may in turn improve the cognitive performance [30]. Third, tooth loss may lead to decreased masticatory

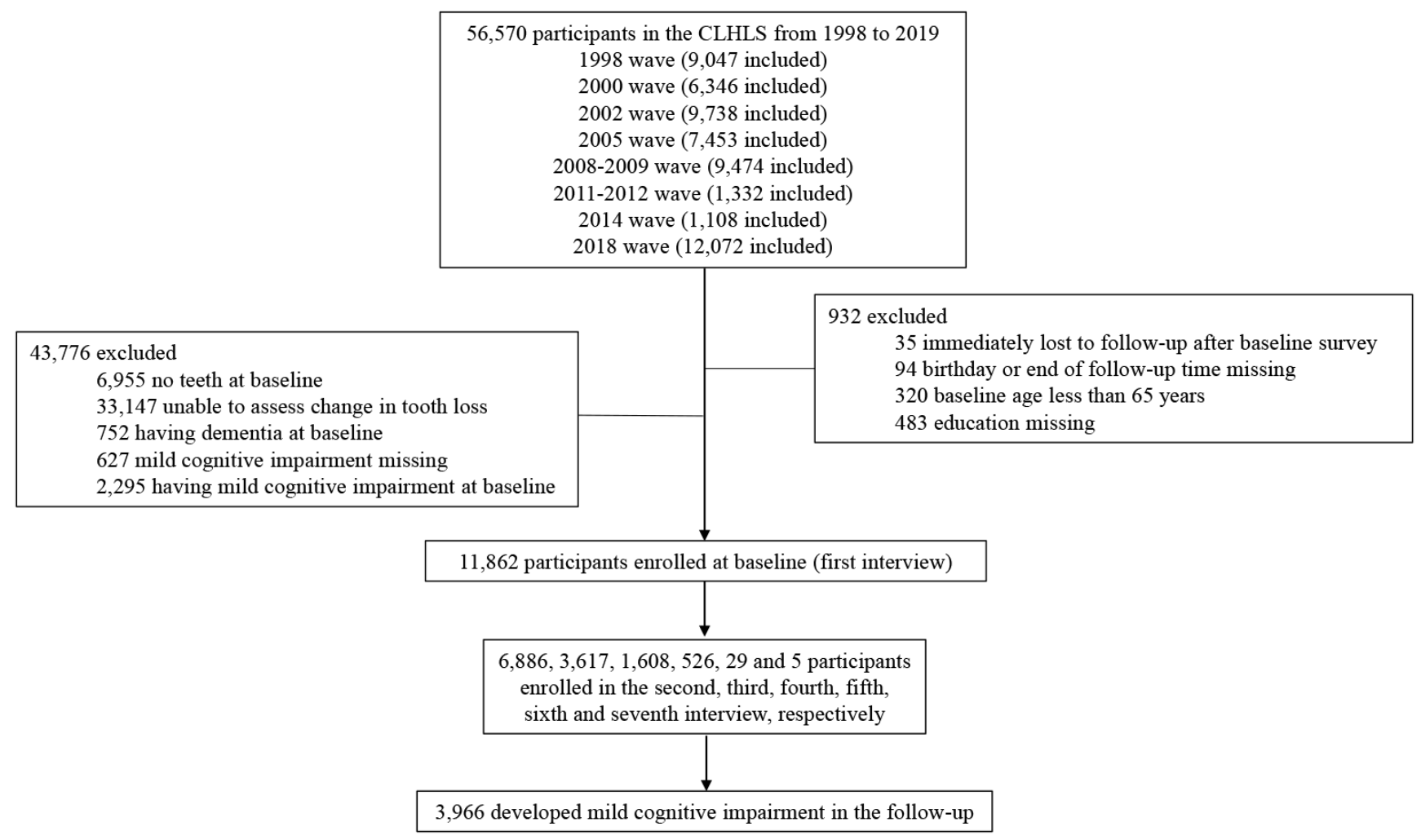

Figure 1. Flow chart of selecting study population from the Chinese longitudinal healthy longevity survey during $1998-2019$. 
Table 2. Association of tooth lose rate with mild cognitive impairment in elderly adults, a longitudinal study in China, 1998 to 2019.

\begin{tabular}{|c|c|c|c|c|c|}
\hline \multirow{2}{*}{ Population } & \multirow{2}{*}{$\begin{array}{c}\text { Tooth lose } \\
\text { rate }\end{array}$} & \multicolumn{4}{|c|}{ Odds ratio ( $95 \%$ confidence intervals) } \\
\hline & & Model 1 & Model 2 & Model 3 & Model 4 \\
\hline \multicolumn{6}{|c|}{ Whole population } \\
\hline & Stable & 1 (Ref.) & 1 (Ref.) & 1 (Ref.) & 1 (Ref.) \\
\hline & Mild & $0.94(0.86-1.04)$ & $0.94(0.86-1.03)$ & $0.95(0.86-1.05)$ & $0.94(0.85-1.03)$ \\
\hline & Middle & $1.11(1.00-1.23)$ & $1.11(1.00-1.23)$ & $1.16(1.04-1.29)$ & $1.16(1.04-1.29)$ \\
\hline & Severe & $1.12(1.03-1.22)$ & $1.14(1.04-1.24)$ & $1.22(1.12-1.33)$ & $1.28(1.17-1.40)$ \\
\hline \multicolumn{6}{|c|}{ Age at baseline, $65-79$ years } \\
\hline & Stable & 1 (Ref.) & 1 (Ref.) & 1 (Ref.) & 1 (Ref.) \\
\hline & Mild & $0.85(0.70-1.03)$ & $0.84(0.69-1.01)$ & $0.83(0.68-1.01)$ & $0.81(0.67-0.99)$ \\
\hline & Middle & $1.13(0.93-1.37)$ & $1.12(0.93-1.36)$ & $1.15(0.94-1.40)$ & $1.14(0.93-1.39)$ \\
\hline & Severe & $1.23(1.06-1.44)$ & $1.26(1.08-1.47)$ & $1.29(1.10-1.52)$ & $1.33(1.13-1.56)$ \\
\hline \multicolumn{6}{|c|}{ Age at baseline, $80-89$ years } \\
\hline & Stable & 1 (Ref.) & 1 (Ref.) & 1 (Ref.) & 1 (Ref.) \\
\hline & Mild & $0.98(0.85-1.12)$ & $0.98(0.85-1.13)$ & $0.99(0.86-1.15)$ & $0.97(0.84-1.12)$ \\
\hline & Middle & $1.04(0.89-1.21)$ & $1.04(0.89-1.22)$ & $1.12(0.95-1.31)$ & $1.12(0.95-1.32)$ \\
\hline & Severe & $1.15(1.01-1.31)$ & $1.17(1.02-1.33)$ & $1.26(1.10-1.44)$ & $1.33(1.15-1.53)$ \\
\hline \multicolumn{6}{|c|}{ Age at baseline, $\geq 90$ years } \\
\hline & Stable & 1 (Ref.) & 1 (Ref.) & 1 (Ref.) & 1 (Ref.) \\
\hline & Mild & $1.00(0.84-1.19)$ & $1.00(0.84-1.18)$ & $1.02(0.85-1.22)$ & $1.01(0.84-1.21)$ \\
\hline & Middle & $1.24(1.02-1.51)$ & $1.23(1.01-1.50)$ & $1.28(1.04-1.57)$ & $1.28(1.04-1.57)$ \\
\hline & Severe & $1.05(0.89-1.24)$ & $1.07(0.90-1.27)$ & $1.17(0.98-1.40)$ & $1.23(1.03-1.48)$ \\
\hline \multicolumn{6}{|l|}{ Male } \\
\hline & Stable & 1 (Ref.) & 1 (Ref.) & 1 (Ref.) & 1 (Ref.) \\
\hline & Mild & $0.95(0.83-1.10)$ & $0.95(0.82-1.09)$ & $0.98(0.85-1.14)$ & $0.97(0.83-1.12)$ \\
\hline & Middle & $1.25(1.08-1.45)$ & $1.25(1.07-1.45)$ & $1.28(1.10-1.50)$ & $1.28(1.10-1.49)$ \\
\hline & Severe & $1.07(0.94-1.21)$ & $1.09(0.96-1.23)$ & $1.17(1.02-1.33)$ & $1.20(1.04-1.37)$ \\
\hline \multicolumn{6}{|l|}{ Female } \\
\hline & Stable & 1 (Ref.) & 1 (Ref.) & 1 (Ref.) & 1 (Ref.) \\
\hline & Mild & $0.94(0.82-1.06)$ & $0.93(0.82-1.06)$ & $0.94(0.82-1.07)$ & $0.92(0.81-1.05)$ \\
\hline & Middle & $1.01(0.87-1.16)$ & $1.00(0.87-1.16)$ & $1.06(0.92-1.23)$ & $1.06(0.92-1.23)$ \\
\hline & Severe & $1.17(1.04-1.31)$ & $1.19(1.06-1.34)$ & $1.28(1.13-1.45)$ & $1.37(1.20-1.55)$ \\
\hline
\end{tabular}

Model 1: adjusted for age, sex, and enrollment year; Model 2: model 1 + further adjusted for province, residence, ethic, marriage status, occupation, education; Model 3: model $2+$ further adjusted for ADL score, physical performance score, food diversity score, social activity score, and chronic disease score; Model 4: model $3+$ further adjusted for No. of teeth at baseline and denture wearing at baseline.

function. Mastication plays a key role in sending sensory information to the brain and in maintaining learning and memory functions of the hippocampus [31]. Masticatory dysfunction has been suggested to be associated with the hippocampal morphological impairments and cognitive decline in elderly adults $[31,32]$.

The strengths of the study included large sample size and abundant covariates, which enables us to construct different models and to conduct a series of subgroup analysis to test the robustness of the results. Meanwhile, teeth number and cognitive function were measured in each wave, so we could observe the trajectory of tooth changes and alterations of cognitive function during follow-up. Furthermore, our study was the first one to explore the dose-response association between number of tooth loss (per year) and risk of MCI. However, there are also several limitations. Although the Mini-Mental State Examination (MMSE) is the most widely used 


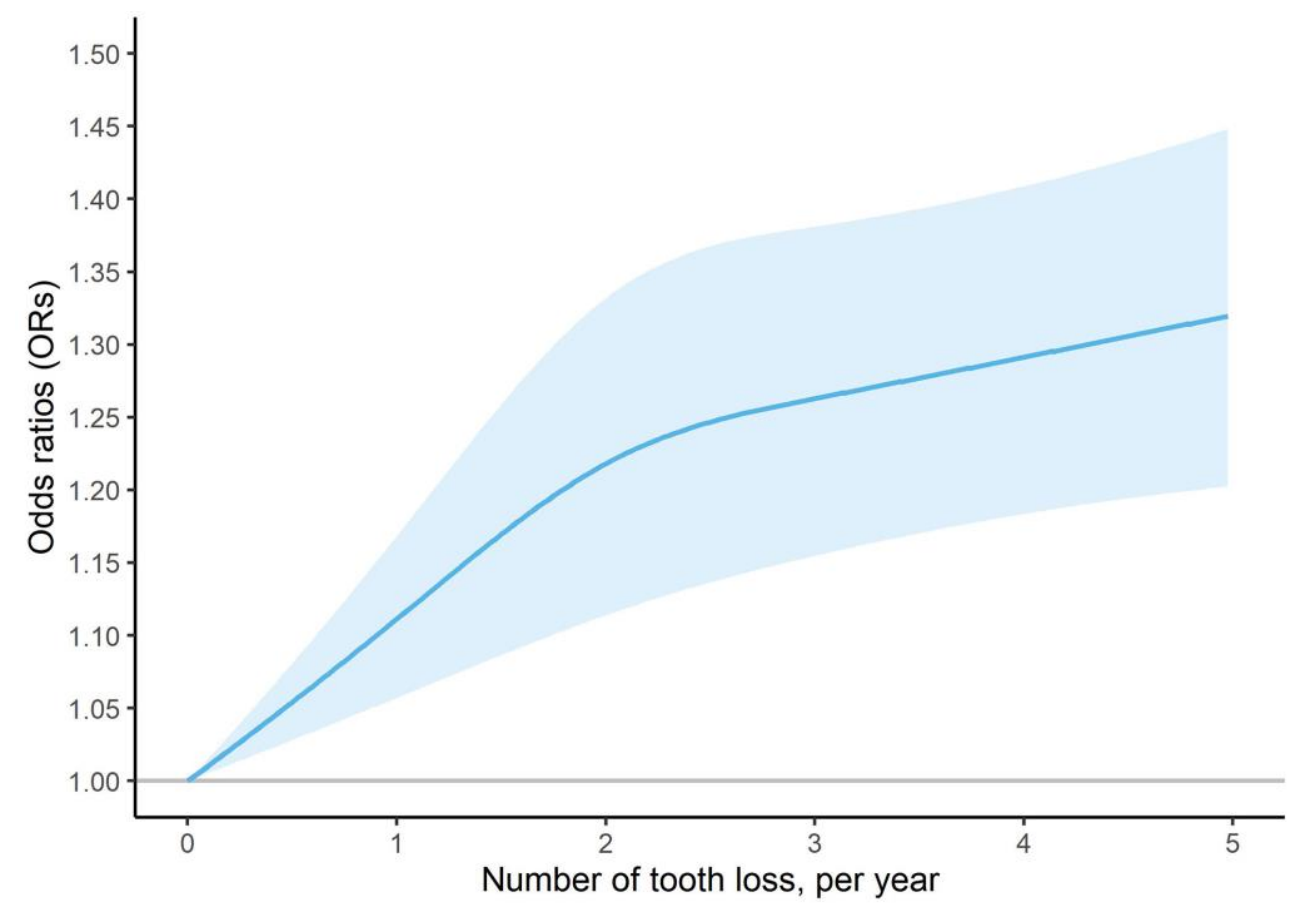

Figure 2. Dose-response association of number of tooth loss (per year) and risk of mild cognitive impairment in the whole population.
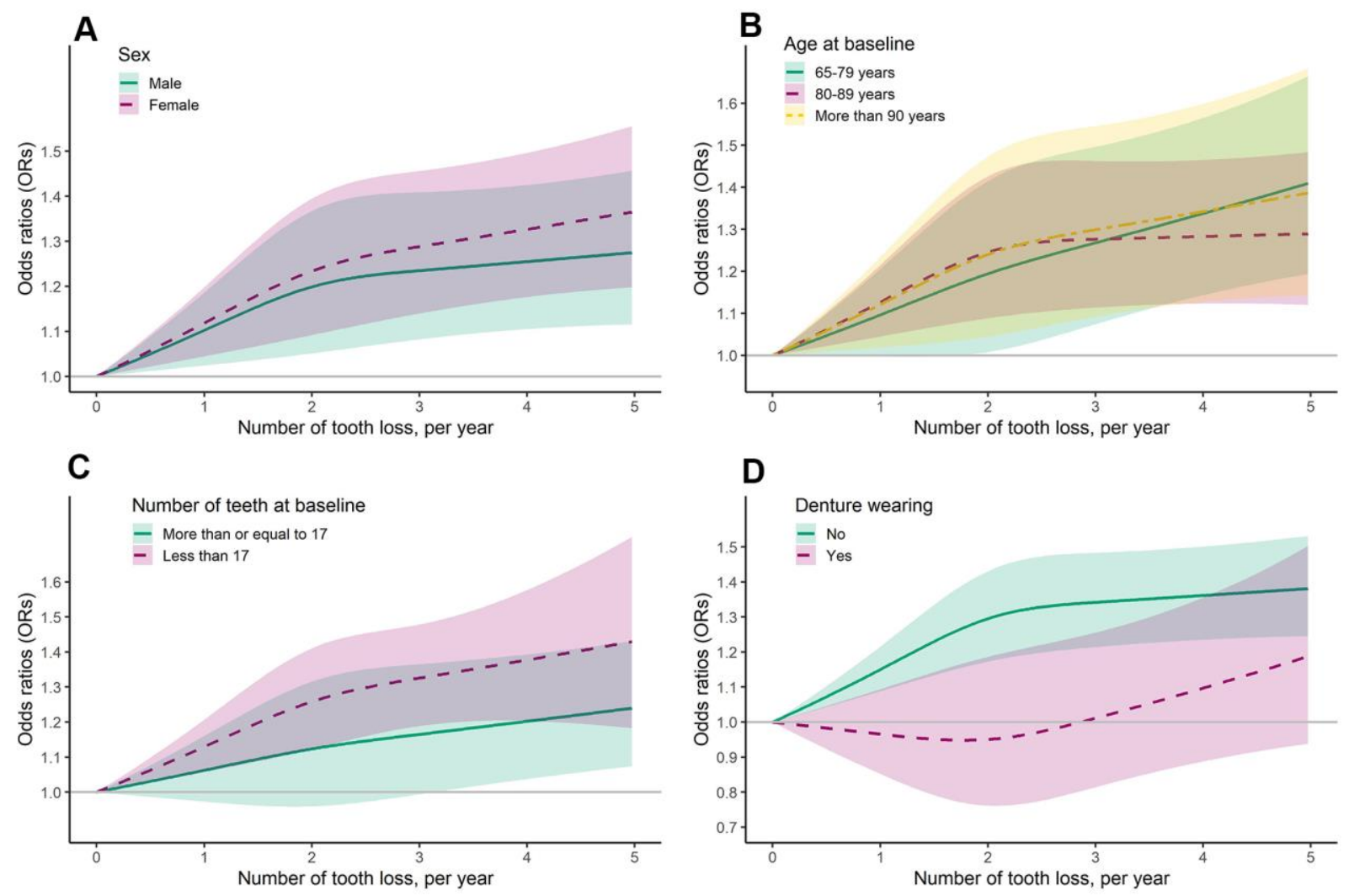

Figure 3. Dose-response association of number of tooth loss (per year) and risk of mild cognitive impairment, stratified by sex (A), age (B), number of teeth (C), and denture wearing (D) at baseline. 
Table 3. Association of tooth lose rate with mild cognitive impairment in elderly adults, stratified by number of teeth and denture wearing at baseline.

\begin{tabular}{|c|c|c|c|c|c|}
\hline \multirow{2}{*}{ Population } & \multirow{2}{*}{$\begin{array}{l}\text { Tooth lose } \\
\text { rate }\end{array}$} & \multicolumn{4}{|c|}{ Odds ratio ( $95 \%$ confidence intervals) } \\
\hline & & Model 1 & Model 2 & Model 3 & Model 4 \\
\hline \multicolumn{6}{|c|}{ No. of teeth at baseline, $\geq 17$} \\
\hline & Stable & 1 (Ref.) & 1 (Ref.) & 1 (Ref.) & 1 (Ref.) \\
\hline & Mild & $0.86(0.70-1.06)$ & $0.86(0.69-1.06)$ & $0.84(0.67-1.05)$ & $0.83(0.67-1.04)$ \\
\hline & Middle & $1.16(0.95-1.42)$ & $1.16(0.94-1.42)$ & $1.16(0.94-1.44)$ & $1.15(0.93-1.42)$ \\
\hline & Severe & $1.17(1.01-1.34)$ & $1.19(1.03-1.37)$ & $1.23(1.06-1.42)$ & $1.21(1.05-1.41)$ \\
\hline \multicolumn{6}{|c|}{ No. of teeth at baseline, $<17$} \\
\hline & Stable & 1 (Ref.) & 1 (Ref.) & 1 (Ref.) & 1 (Ref.) \\
\hline & Mild & $0.96(0.86-1.06)$ & $0.95(0.86-1.06)$ & $0.98(0.87-1.09)$ & $0.97(0.87-1.08)$ \\
\hline & Middle & $1.10(0.98-1.24)$ & $1.10(0.97-1.24)$ & $1.17(1.03-1.32)$ & $1.16(1.03-1.31)$ \\
\hline & Severe & $1.23(1.09-1.38)$ & $1.25(1.11-1.41)$ & $1.34(1.18-1.51)$ & $1.34(1.18-1.51)$ \\
\hline \multicolumn{6}{|c|}{ Denture wearing, No } \\
\hline & Stable & 1 (Ref.) & 1 (Ref.) & 1 (Ref.) & 1 (Ref.) \\
\hline & Mild & $0.97(0.88-1.08)$ & $0.97(0.87-1.08)$ & $0.99(0.89-1.10)$ & $0.98(0.88-1.09)$ \\
\hline & Middle & $1.14(1.02-1.28)$ & $1.14(1.02-1.28)$ & $1.19(1.05-1.34)$ & $1.19(1.06-1.35)$ \\
\hline & Severe & $1.13(1.03-1.25)$ & $1.16(1.06-1.28)$ & $1.25(1.14-1.38)$ & $1.35(1.22-1.50)$ \\
\hline \multicolumn{6}{|c|}{ Denture wearing, Yes } \\
\hline & Stable & 1 (Ref.) & 1 (Ref.) & 1 (Ref.) & 1 (Ref.) \\
\hline & Mild & $0.79(0.63-0.99)$ & $0.80(0.63-1.00)$ & $0.80(0.63-1.02)$ & $0.80(0.63-1.02)$ \\
\hline & Middle & $1.00(0.78-1.27)$ & $1.00(0.79-1.28)$ & $1.11(0.87-1.41)$ & $1.11(0.87-1.41)$ \\
\hline & Severe & $0.96(0.77-1.20)$ & $0.97(0.77-1.21)$ & $1.02(0.81-1.28)$ & $1.04(0.82-1.30)$ \\
\hline
\end{tabular}

Model 1: adjusted for age, sex, and enrollment year; Model 2: model $1+$ further adjusted for province, residence, ethic, marriage status, occupation, education; Model 3: model $2+$ further adjusted for ADL score, physical performance score, food diversity score, social activity score, and chronic disease score; Model 4: model $3+$ further adjusted for number of teeth and denture wearing at baseline.

tool for identifying cognitive impairment, [33] its assessment may be biased due to differences of age, race, and education background [33]. Besides, there has a ceiling effect of MMSE, which may not be sensitive for MCI [33]. Second, self-reported teeth number may lead to misclassification of exposure status. However, self-reported teeth number has been widely used in previous epidemiological studies and strongly correlated with clinical records [34]. Third, lacking information on the detailed oral health, such as periodontal disease and denture type, makes us unable to explore whether the association between number of tooth loss and MCI was affected by those factors. Moreover, there was no detailed information on denture wearing during the follow-up, which may lead to misclassification of denture wearing to some extent as some participants may switch to other groups (e.g., from denture nonwearer to wearer). Therefore, replication from future study is needed, especially those with rich information on oral health. Fourth, individuals with MCI may be less likely to pay attention to their oral hygiene compared with those without MCI; reverse causation cannot be ruled out. Our findings therefore are only suggestive and cannot prove causality. Fifth, since this study was conducted in elderly adults in China, generalization of the findings to other population should be cautious.

In the present longitudinal study, we found that higher rate of tooth loss was associated with increased risk of MCI in elderly adults in China. Denture wearing however may provide a protective effect against the developing of MCI. Further studies are needed to investigate the potential mechanisms underlying the observed association. Our findings may have clinical implications on improvement of oral health to reduce potential risk of cognitive impairment in elderly adults.

\section{MATERIALS AND METHODS}

\section{Study population}

The Chinese Longitudinal Healthy Longevity Survey (CLHLS) is an ongoing longitudinal study of the 
elderly adults [35]. It started in 1998, and a series of follow-up surveys was conducted in 2000, 2002, 2005, 2008-2009, 2011-2012, 2014, and 2018-2019, respectively. In order to well-represent elderly adults in China and maintain enough sample size, new participants were added to the survey in the follow-up waves. We enrolled all participants (1998 wave), survivors and new participants (consequent waves) in the present study $(n=56,570)$, and over $74 \%$ participants were firstly interviewed before 2011-2012 wave (Figure 1). Participants with the following reasons were excluded from the analysis: (1) immediately lost to follow up after baseline survey $(n=35)$; (2) birthday or end of follow up time missing $(\mathrm{n}=94)$; (3) baseline age less than 65 years $(n=320)$; (4) education missing $(\mathrm{n}=483)$; (5) no teeth at baseline $(\mathrm{n}=6,955)$; (6) unable to assess change in teeth loss $(\mathrm{n}=33,147)$; (7) having dementia at baseline $(\mathrm{n}=$ 752); (8) MCI missing ( $\mathrm{n}=627)$; or (9) having MCI at baseline $(n=2,295)$. Eventually, a total of 11,862 participants were enrolled in the final analysis. Among them, 6,886, 3,617, 1,608, 526, 29 and 5 participants had two, three, four, five, six and seven times of interview (Figure 1). Research Ethics Committees of Peking University approved the CLHLS, and written informed consents from all participants or their representatives were collected.

\section{Exposure, outcome and important covariates assessments}

Self-reported information on number of natural teeth as well as the denture wearing (yes/no) was repeatedly collected and updated in each wave with the following questions: 1) How many natural teeth do you still have? 2) Do you have false teeth? Tooth loss rate was defined as the difference of teeth between two interview waves divided by years of interval. Participants were grouped into four categories by the following criteria: stable, no tooth loss; mild, 0-1 tooth loss; middle, 1-2 tooth loss; and severe, more than 2 tooth loss per year. The interviewer would help participants with hearing impairment to confirm their answers, which could largely ensure the validity of self-reported information on natural teeth and denture wearing.

Cognitive function was assessed by the Chinese version of MMSE at each wave. It contains twenty-four items regarding orientation, registration, attention, calculation, recall and language, with a total score ranging from 0 to 30; a higher score indicates a better cognitive function [36]. As cognitive performance was closely associated with educational level, different cut-off points across education levels were applied to define MCI: illiterate: $<18$; those with level of primary school: $<21$; and those with level of middle school or above: $<25$ [37].
Age, gender and ethnicity were measured at baseline; all other covariates, such as residence, marriage status, occupation, education, smoking and drinking, activities of daily life (ADL) score, physical performance score, food diversity score, social activity score, and chronic disease score, were measured at baseline and at each follow-up interview. The definition of the abovementioned scores were described in previous study [38].

\section{Statistical analysis}

Continuous variables were compared via ANOVA test, while categorical variables were compared via Chisquared test. As one participant may have multiple records in the whole survey period and those records were statistically dependent, a generalized estimating equation (GEE) model was used to estimate the odds ratio (OR) and the $95 \%$ confidence intervals (CIs) with adjustment for potential confounders. In model 1 , we adjusted for age, sex, and enrollment year. In model 2, we further adjusted for province, residence, ethic, marriage status, occupation and education. Covariates in model 2 plus the following covariates were further adjusted for in the model 3: ADL score, physical performance score, food diversity score, social activity score, and chronic disease score. Number of teeth at baseline and denture wearing were further adjusted for in the model 4. Subgroup analyses stratified by sex, age, number of teeth and denture wearing at baseline were also conducted to explore whether the results were consistent across different subgroup population.

To further explore the dose-response association between number of tooth loss per year and risk of MCI in the whole and subgroup population, restricted cubic spline function with 3 knots selected at number of tooth loss per year of " $1,2,3$ " was applied in the GEE model. The reference value for number of tooth loss per year was zero.

All analyses were conducted using SAS 9.4 (SAS Institute Inc, Cary, NC, USA) and R platform. A $P$ value less than 0.05 was considered statistically significant.

\section{Abbreviations}

MCI: Mild cognitive impairment; CLHLS: Chinese Longitudinal Healthy Longevity Survey; GEE: generalized estimating equation; OR: odds ratio; CI: confidence intervals; ADL: activities of daily life; MMSE: Mini-Mental State Examination.

\section{AUTHOR CONTRIBUTIONS}

JS designed the study and analyzed the results; SX, $\mathrm{XH}, \mathrm{YG}$ and JS drafted the paper. SX, XH, YG and JS 
have contributed to the interpretation of findings and provided revisions to the manuscript. All authors have read and approved the final manuscript.

\section{ACKNOWLEDGMENTS}

The authors would like to thank the participants of CLHLS for their contributions to this project.

\section{CONFLICTS OF INTEREST}

The authors declare that they have no conflicts of interest.

\section{FUNDING}

This study is supported by the Shanghai Municipal Health Commission Foundation (Grant number 20204Y0096) and China Scholarship Council.

\section{REFERENCES}

1. Murman DL. The Impact of Age on Cognition. Semin Hear. 2015; 36:111-21.

https://doi.org/10.1055/s-0035-1555115

PMID:27516712

2. Gauthier S, Reisberg B, Zaudig M, Petersen RC, Ritchie K, Broich K, Belleville S, Brodaty H, Bennett $D$, Chertkow $\mathrm{H}$, Cummings JL, de Leon $\mathrm{M}$, Feldman $\mathrm{H}$, et al, and International Psychogeriatric Association Expert Conference on mild cognitive impairment. Mild cognitive impairment. Lancet. 2006; 367:1262-70.

https://doi.org/10.1016/S0140-6736(06)68542-5

PMID:16631882

3. Gillis C, Mirzaei F, Potashman M, Ikram MA, Maserejian $N$. The incidence of mild cognitive impairment: A systematic review and data synthesis. Alzheimers Dement (Amst). 2019; 11:248-56. https://doi.org/10.1016/j.dadm.2019.01.004 PMID:30911599

4. Li W, Sun L, Xiao S. Prevalence, Incidence, Influence Factors, and Cognitive Characteristics of Amnestic Mild Cognitive Impairment Among Older Adult: A 1-Year Follow-Up Study in China. Front Psychiatry. 2020; 11:75.

https://doi.org/10.3389/fpsyt.2020.00075

PMID:32184742

5. Jia L, Du Y, Chu L, Zhang Z, Li F, Lyu D, Li Y, Li Y, Zhu M, Jiao $H$, Song $Y$, Shi $Y$, Zhang $H$, et al, and COAST Group. Prevalence, risk factors, and management of dementia and mild cognitive impairment in adults aged 60 years or older in China: a cross-sectional study. Lancet Public Health. 2020; 5:e661-71.
https://doi.org/10.1016/S2468-2667(20)30185-7 PMID:33271079

6. Wimo A, Jonsson L, Winblad B. An estimate of the worldwide prevalence and direct costs of dementia in 2003. Dement Geriatr Cogn Disord. 2006; 21:175-81. https://doi.org/10.1159/000090733 PMID:16401889

7. Panza F, D'Introno A, Colacicco AM, Capurso C, Del Parigi A, Caselli RJ, Pilotto A, Argentieri G, Scapicchio PL, Scafato E, Capurso A, Solfrizzi V. Current epidemiology of mild cognitive impairment and other predementia syndromes. Am J Geriatr Psychiatry. 2005; 13:633-44.

https://doi.org/10.1176/appi.ajgp.13.8.633 PMID: $\underline{16085779}$

8. Hu C, Wang L, Guo Y, Cao Z, Lu Y, Qin H. Study of the Risk and Preventive Factors for Progress of Mild Cognitive Impairment to Dementia. Am J Alzheimers Dis Other Demen. 2020; 35:1533317520925324.

https://doi.org/10.1177/1533317520925324 PMID:32567328

9. Hu C, Wang L, Zhao X, Zhu B, Tian M, Qin H. Investigation of risk factors for the conversion of mild cognitive impairment to dementia. Int J Neurosci. 2020. [Epub ahead of print].

https://doi.org/10.1080/00207454.2020.1782905 PMID:32532166

10. Song YN, Wang P, Xu W, Li JQ, Cao XP, Yu JT, Tan L. Risk Factors of Rapid Cognitive Decline in Alzheimer's Disease and Mild Cognitive Impairment: A Systematic Review and Meta-Analysis. J Alzheimers Dis. 2018; 66:497-515.

https://doi.org/10.3233/JAD-180476 PMID:30320579

11. Raphael C. Oral Health and Aging. Am J Public Health. 2017; 107:S44-45.

https://doi.org/10.2105/AJPH.2017.303835

PMID:28661797

12. Lauritano D, Moreo G, Della Vella F, Di Stasio D, Carinci F, Lucchese A, Petruzzi M. Oral Health Status and Need for Oral Care in an Aging Population: A Systematic Review. Int J Environ Res Public Health. 2019; 16:4558. https://doi.org/10.3390/ijerph16224558 PMID:31752149

13. Cerutti-Kopplin D, Feine J, Padilha DM, de Souza RF, Ahmadi M, Rompré $P$, Booij L, Emami E. Tooth Loss Increases the Risk of Diminished Cognitive Function: A Systematic Review and Meta-analysis. JDR Clin Trans Res. 2016; 1:10-19.

https://doi.org/10.1177/2380084416633102 PMID:30931697

14. Li J, Xu H, Pan W, Wu B. Association between tooth loss and cognitive decline: A 13-year longitudinal study of Chinese older adults. PLoS One. 2017; 12:e0171404. 
https://doi.org/10.1371/journal.pone.0171404 PMID:28158261

15. Aida J, Kondo K, Yamamoto $T$, Hirai $H$, Nakade $M$, Osaka K, Sheiham A, Tsakos G, Watt RG. Oral health and cancer, cardiovascular, and respiratory mortality of Japanese. J Dent Res. 2011; 90:1129-35.

https://doi.org/10.1177/0022034511414423 PMID:21730255

16. Polzer I, Schwahn C, Völzke H, Mundt T, Biffar R. The association of tooth loss with all-cause and circulatory mortality. Is there a benefit of replaced teeth? A systematic review and meta-analysis. Clin Oral Investig. 2012; 16:333-51. https://doi.org/10.1007/s00784-011-0625-9 PMID:22086361

17. Stewart R, Weyant RJ, Garcia ME, Harris T, Launer $L$, Satterfield S, Simonsick EM, Yaffe K, Newman AB. Adverse oral health and cognitive decline: the health, aging and body composition study. J Am Geriatr Soc. 2013; 61:177-84. https://doi.org/10.1111/igs.12094 PMID:23405916

18. Tsakos G, Watt RG, Rouxel PL, de Oliveira C, Demakakos P. Tooth loss associated with physical and cognitive decline in older adults. J Am Geriatr Soc. 2015; 63:91-99.

https://doi.org/10.1111/igs.13190 PMID:25523131

19. Naorungroj S, Schoenbach VJ, Wruck L, Mosley TH, Gottesman RF, Alonso A, Heiss G, Beck J, Slade GD. Tooth loss, periodontal disease, and cognitive decline in the Atherosclerosis Risk in Communities (ARIC) study. Community Dent Oral Epidemiol. 2015; 43:47-57.

https://doi.org/10.1111/cdoe.12128 PMID:25363061

20. Kaye EK, Valencia A, Baba N, Spiro A 3rd, Dietrich T, Garcia RI. Tooth loss and periodontal disease predict poor cognitive function in older men. J Am Geriatr Soc. 2010; 58:713-18.

https://doi.org/10.1111/i.1532-5415.2010.02788.x PMID:20398152

21. Tonsekar PP, Jiang SS, Yue G. Periodontal disease, tooth loss and dementia: Is there a link? A systematic review. Gerodontology. 2017; 34:151-63.

https://doi.org/10.1111/ger.12261 PMID:28168759

22. Sansores-España D, Carrillo-Avila A, Melgar-Rodriguez S, Díaz-Zuñiga J, Martínez-Aguilar V. Periodontitis and Alzheimer's disease. Med Oral Patol Oral Cir Bucal. 2021; 26:e43-48.

https://doi.org/10.4317/medoral.23940

PMID:32701930

23. Gil Montoya JA, Barrios R, Sanchez-Lara I, Ramos P, Carnero C, Fornieles F, Montes J, Santana S, Luna JD, Gonzalez-Moles MA. Systemic inflammatory impact of periodontitis on cognitive impairment. Gerodontology. 2020; 37:11-18.

https://doi.org/10.1111/ger.12431 PMID:31347730

24. Kamer AR, Craig RG, Dasanayake AP, Brys M, GlodzikSobanska L, de Leon MJ. Inflammation and Alzheimer's disease: possible role of periodontal diseases. Alzheimers Dement. 2008; 4:242-50. https://doi.org/10.1016/j.jalz.2007.08.004 PMID:18631974

25. Bretz WA, Weyant RJ, Corby PM, Ren D, Weissfeld L, Kritchevsky SB, Harris T, Kurella M, Satterfield S, Visser $M$, Newman AB. Systemic inflammatory markers, periodontal diseases, and periodontal infections in an elderly population. J Am Geriatr Soc. 2005; 53:1532-37. https://doi.org/10.1111/j.1532-5415.2005.53468.x PMID:16137283

26. Tucker KL, Qiao N, Scott T, Rosenberg I, Spiro A 3rd. High homocysteine and low $B$ vitamins predict cognitive decline in aging men: the Veterans Affairs Normative Aging Study. Am J Clin Nutr. 2005; 82:627-35.

https://doi.org/10.1093/ajcn.82.3.627 PMID:16155277

27. Ross SM. The Nutrition-Brain Connection: Nutritional Status and Cognitive Decline. Holist Nurs Pract. 2018; 32:169-71.

https://doi.org/10.1097/HNP.0000000000000270 PMID:29642132

28. Yang WS, Shu XO, Gao J, Li HL, Cai H, Yang G, Ji BT, Rothman N, Gao YT, Zheng W, Xiang YB. Prospective evaluation of type 2 diabetes mellitus on the risk of primary liver cancer in Chinese men and women. Ann Oncol. 2013; 24:1679-85.

https://doi.org/10.1093/annonc/mdt017 PMID:23406734

29. Gómez-Gómez ME, Zapico SC. Frailty, Cognitive Decline, Neurodegenerative Diseases and Nutrition Interventions. Int J Mol Sci. 2019; 20:2842.

https://doi.org/10.3390/ijms20112842 PMID:31212645

30. Felton D, Cooper L, Duqum I, Minsley G, Guckes A, Haug S, Meredith P, Solie C, Avery D, Chandler ND, and American College of Prosthodontists, and Academy of General Dentistry, and American Dental Association Council on Scientific Affairs, and American Dental Hygienists' Association, and National Association of Dental Laboratories, and GlaxoSmithKline Consumer Healthcare. Evidence-based guidelines for the care and maintenance of complete dentures: a publication of the American College of Prosthodontists. J Am Dent Assoc. 2011 (Suppl 1); 142:1S-20S.

https://doi.org/10.14219/jada.archive.2011.0067 PMID:21282672 
31. Ono Y, Yamamoto T, Kubo KY, Onozuka M. Occlusion and brain function: mastication as a prevention of cognitive dysfunction. J Oral Rehabil. 2010; 37:624-40. https://doi.org/10.1111/i.1365-2842.2010.02079.x PMID:20236235

32. Chen $H$, linuma $M$, Onozuka $M$, Kubo KY. Chewing Maintains Hippocampus-Dependent Cognitive Function. Int J Med Sci. 2015; 12:502-09. https://doi.org/10.7150/ijms.11911 PMID:26078711

33. Devenney E, Hodges JR. The Mini-Mental State Examination: pitfalls and limitations. Pract Neurol. 2017; 17:79-80. https://doi.org/10.1136/practneurol-2016-001520 PMID:27903765

34. Pitiphat W, Garcia RI, Douglass CW, Joshipura KJ. Validation of self-reported oral health measures. J Public Health Dent. 2002; 62:122-28. https://doi.org/10.1111/j.1752-7325.2002.tb03432.x PMID:11989207

35. Zeng Y. Towards Deeper Research and Better Policy for Healthy Aging --Using the Unique Data of Chinese Longitudinal Healthy Longevity Survey. China Economic J. 2012; 5:131-49. https://doi.org/10.1080/17538963.2013.764677 PMID:24443653

36. Li H, Jia J, Yang Z. Mini-Mental State Examination in Elderly Chinese: A Population-Based Normative Study. J Alzheimers Dis. 2016; 53:487-96. https://doi.org/10.3233/JAD-160119 PMID:27163822

37. Katzman R, Zhang MY, Ouang-Ya-Qu, Wang ZY, Liu WT, Yu E, Wong SC, Salmon DP, Grant I. A Chinese version of the Mini-Mental State Examination; impact of illiteracy in a Shanghai dementia survey. J Clin Epidemiol. 1988; 41:971-78. https://doi.org/10.1016/0895-4356(88)90034-0 PMID:3193141

38. Sun J, Li L, Sun J. Sensory impairment and all-cause mortality among the elderly adults in China: a population-based cohort study. Aging (Albany NY). 2020; 12:24288-300. https://doi.org/10.18632/aging.202198 PMID: $\underline{3260148}$ 